\title{
High glucose-induced apoptosis in human coronary artery endothelial cells involves up-regulation of death receptors
}

Shun-ichiro Kageyama ${ }^{1}$, Hiroki Yokoo ${ }^{1}$, Kengo Tomita ${ }^{1}$, Natsuko Kageyama-Yahara ${ }^{2}$, Ryo Uchimido ${ }^{1}$, Naoyuki Matsuda', Seiji Yamamoto ${ }^{1}$ and Yuichi Hattori ${ }^{{ }^{*}}$

\begin{abstract}
Background: High glucose can induce apoptosis in vascular endothelial cells, which may contribute to the development of vascular complications in diabetes. We evaluated the role of the death receptor pathway of apoptotic signaling in high glucose-induced apoptosis in human coronary artery endothelial cells (HCAECs).

Methods: HCAECs were treated with media containing 5.6, 11.1, and $16.7 \mathrm{mM}$ of glucose for $24 \mathrm{~h}$ in the presence or absence of tumor necrosis factor (TNF)- $\alpha$. For detection of apoptosis, DNA fragmentation assay was used. HCAEC expression of death receptors were analyzed by the PCR and flow cytometry methods. Also, using immunohistochemical techniques, coronary expression of death receptors was assessed in streptozotocinnicotinamide-induced type 2 diabetic mice.

Results: Exposure of HCAECS to high glucose resulted in a significant increase in TNF-R1 and Fas expression, compared with normal glucose. High glucose increased TNF- $\alpha$ production by HCAECs and exogenous TNF- $\alpha$ upregulated TNF-R1 and Fas expression in HCAECs. High glucose-induced up-regulation of TNF-R1 and Fas expression was undetectable in the presence of TNF- $\alpha$. Treatment with TNF-R1 neutralizing peptides significantly inhibited high glucose-induced endothelial cell apoptosis. Type 2 diabetic mice displayed appreciable expression of TNF-R1 and Fas in coronary vessels.

Conclusions: In association with increased TNF- $\alpha$ levels, the death receptors, TNF-R1 and Fas, are up-regulated in HCAECs under high glucose conditions, which could in turn play a role in high glucose-induced endothelial cell apoptosis.
\end{abstract}

\section{Background}

Vascular complications are a leading cause of morbidity and mortality in diabetes. A wide variety of studies suggest that endothelial dysfunction and damage present pathophysiological early steps for the development of vascular complications $[1,2]$. A growing body of evidence indicates the close correlation between hyperglycemia and the abnormalities in endothelial function and morphology. High ambient glucose has been shown to disturb cell cycle [3,4], increase DNA damage [5], delay endothelial cell replication [3], and cause excessive cell

\footnotetext{
* Correspondence: yhattori@med.u-toyama.ac.jp

'Department of Molecular and Medical Pharmacology, Graduate School of Medicine and Pharmaceutical Sciences, University of Toyama, Toyama 9300194, Japan

Full list of author information is available at the end of the article
}

death [3] in cultured human endothelial cells. More critically, that high glucose selectively triggers apoptosis in cultured endothelial cells has been demonstrated by subsequent studies from different laboratories [6-10]. An accelerated programmed cell death of retinal microvascular cells has been reported to occur in situ in human and experimental diabetic retinopathy [11,12]. Moreover, significant apoptosis of endothelial cells has been found in ventricular myocardial biopsies obtained from diabetic patients [13]. Several downstream pathways affected by hyperglycemia, such as oxidative stress $[8-10,14,15]$ and glycation $[16,17]$, are thought to stimulate apoptosis in endothelial cells. In contrast to its effect on endothelial cells, high glucose has been reported to inhibit apoptosis in coronary artery smooth 
muscle cells by up-regulating anti-apoptotic proteins [18]. Thus, the molecular events linking high glucose with the apoptotic machinery of endothelial cells may be far more complicated than being realized.

Apoptotic cell death in mammals can proceed by two distinct pathways that ultimately converge into a common pathway causing the activation of the effector enzymes caspases. The intrinsic pathway feeds cell death signals through the mitochondrion, which appears to act as a genetic damage sensor and monitor of metabolic status. Thus, injured mitochondria can release cytochrome $c$ into the cytoplasm, where it can bind to apoptotic protease activating factor (APAF)- 1 and activate caspase networks that induce apoptosis $[19,20]$. Recent report has shown that exposure to high glucose results in a decrease in the mitochondrial membrane potential and a release of cytochrome $c$ in human umbilical vein endothelial cells [21]. Furthermore, high glucose treatment has been found to cause an increase in protein expression of Bax, whose complex formation is associated with cytosolic release of cytochrome $c$, in human aortic endothelial cells [22]. Proapoptotic signaling can also be mediated by the death receptor pathway. This extrinsic pathway transduces the signals of extracellular 'death ligands' which are members of the tumor necrosis factor (TNF) superfamily. After ligand binding to the intracellular death domain on the receptors, including TNF receptor 1 (TNF-R1) and Fas, the activated death receptors recruit adaptor proteins, which in turn recruit procaspase- 8 into a proapoptotic complex termed the death-inducing signaling complex (DISC). Then, the initiator procaspase- 8 is activated proteolytically into caspase- 8 and further activates effector caspases along the common pathway of apoptosis $[23,24]$. One study has revealed that reduced $\mathrm{T}$ cell Fas ligand expression prevents diabetes in NOD mice [25], and several similar studies have focused on the importance of Fas in beta cell death and the development of diabetes [26,27], although evidence against a role of Fas has also been presented $[28,29]$. Nevertheless, data about a potential role of the death receptor apoptotic signaling pathway in the high glucose-induced apoptotic process in endothelial cells are still missing. Such information is important for understanding molecular mechanisms underlying high glucoseinduced endothelial cell apoptosis.

In the present study, we initially examined whether high ambient glucose up-regulates expression of death receptors in cultured human coronary artery endothelial cells (HCAECs). We found that gene expression levels of the death receptors, TNF-R1 and Fas, were strikingly increased in endothelial cells under high-glucose conditions. Next, we investigated the possible involvement of the death receptor pathway of apoptotic signaling in high glucose-induced apoptosis in endothelial cells. Finally, we evaluated the possibility that coronary arteriolar endothelium may significantly express TNF-R1 and Fas in type 2 diabetic mice.

\section{Materials and methods \\ Endothelial cell culture}

HCAECs were purchased from Cambrex Bioscience (Walkersville, MD). Cells were used between passages 6 and 7 for experiments to avoid effects of in vitro cell aging. Cells were grown in endothelial growth media-2 (EGM-2; Cambrex) supplemented with growth factors and $5 \%(\mathrm{v} / \mathrm{v})$ fetal bovine serum to $70-80 \%$ confluency. Cells were cultured in a humidified incubator at $37^{\circ} \mathrm{C}$ with a $5 \% \mathrm{CO}_{2}$ atmosphere and the medium was changed every second day. To determine the effect of high glucose or TNF- $\alpha$ on cell apoptosis and death receptor expression, cells were incubated with both zero growth factors and zero hydrocortisone for $30 \mathrm{~h}$, and they were then cultured for $24 \mathrm{~h}$ under different concentrations of glucose (5.6, 11.1 and $16.7 \mathrm{mM})$.

\section{Reverse transcription PCR (RT-PCR)}

Total RNA was isolated from cells using standard procedure, including ISOGEN (Nippon Gene, Tokyo, Japan). The RNA was reverse-transcribed in a $20-\mu$ l reaction mixture that contained 5 U ReverScript ${ }^{\circledR}$ III (Wako, Osaka, Japan) and $0.5 \mu \mathrm{g}$ oligo(dT)12-18 primer (Invitrogen, Carlsbad, CA) at $42^{\circ} \mathrm{C}$ for $1 \mathrm{~h}$, followed by $51^{\circ} \mathrm{C}$ for $30 \mathrm{~min}$. The primer pairs for TNF-R1 (forward, 5'-GAG AGG CCA TAG CTG TCT GG-3'; reverse, 5'-GTT CCT TTG TGG CAC TTG GT-3'), for Fas (forward, 5'-TCA GTA CGG AGT TGG GGA AG-3'; reverse, 5'-CAG GCC TTC CAA GTT CTG AG-3'), for DR4 (forward, 5'AGA GAG AAG TCC CTG CAC CA-3'; reverse, 5'-GTC ACT CCA GGG CGT ACA AT-3'), and for DR5 (forward, 5'-CAC CAG GTG TGA TTC AGG TG-3'; reverse, 5'-CCC CAC TGT GCT TTG TAC CT-3') yielded a 218-, 207-, 154-, and 221-bp PCR product, respectively. Human $\beta$-actin (forward, 5'-GGA CTT CGA GCA AGA GAT GG-3'; reverse, 5'-AGC ACT GTG TTG GCG TAC AG-3') was used as a reference gene. PCR was performed using an iCycler (Bio-Rad, Tokyo, Japan). The reaction mixture consisted of template cDNA, $0.2 \mu \mathrm{M}$ of each primer, $300 \mu \mathrm{M}$ dNTPs, 3 $\mathrm{mM} \mathrm{MgCl}_{2}$, and $0.05 \mathrm{U} / \mu \mathrm{l}$ ExTaq DNA polymerase (Takara Shuzo, Ohtsu, Japan). PCR was performed for 32 cycles for each gene with denaturation at $95^{\circ} \mathrm{C}$ for $15 \mathrm{~s}$, annealing at $61^{\circ} \mathrm{C}$ for $15 \mathrm{~s}$, and extension at $72^{\circ} \mathrm{C}$ for $20 \mathrm{~s}$. PCR products were quantified using NIH Image.

\section{Quantitative real-time PCR}

Real-time PCR was performed in a final volume of $20 \mu \mathrm{l}$ containing cDNA template and primers using Takara RNA PCR kit (Takara Shuzo) as described in the manufacture's manual. PCR amplification was carried out on 
the genomic DNA using the following primers: TNF-R1, forward 5'-AAC AGA ACA CCG TGT GCA CCT-3' and reverse 5'-AGT CCT CAG TGC CCT TAA CAT TCT C-3'; FAS, forward 5'-AGA GTA AAT GCA GTG GCA TGC TAA G-3' and reverse 5'-GGG TTA GCC TGT GGA TAG ACA TTT G-3'; DR4, forward 5'-GGA ACA CAG CAT GTC AGT GCA A-3' and reverse 5'TGT CAC TCC AGG GCG TAC AAT C-3'; DR5, forward 5'-CAT CTA TGG ACA GGC TGG GAC A-3' and reverse 5'-CCC AAA CAG GGC TCA AGT TCA3'; and actin, forward 5'-TGG CAC CCA GCA CAA TGA A-3' and reverse 5'-CTA AGT CAT AGT CCG CCT AGA AGC A-3'. The PCR program consisted of $95^{\circ} \mathrm{C}$ for $30 \mathrm{~s}$ for initial denaturation of DNA, followed by 40 cycles of $95^{\circ} \mathrm{C}$ for $5 \mathrm{~s}, 60^{\circ} \mathrm{C}$ for $34 \mathrm{~s}$ for annealing of primers, and $95^{\circ} \mathrm{C}$ for $1 \mathrm{~min}$ for elongation. The PCR product size for TNF-R1, FAS, DR4, DR5, and actin was $141,150,130,96$, and $186 \mathrm{bp}$, respectively; they were visualized after agarose gel electrodes and ethidium bromide staining. Actin served as an internal control for normalization.

\section{Immunocytochemistry and TUNEL staining}

After being fixed with 4\% paraformaldehyde for $15 \mathrm{~min}$ at room temperature, cells were kept in PBS at $4^{\circ} \mathrm{C}$ until staining. Unspecific binding sites were blocked in PBS containing $10 \%$ normal goat sera. The samples were treated with rabbit anti-human von Willebrand factor (vWF) antibody (Chemicon, Temecula, CA) at 1:100 dilution overnight at $4{ }^{\circ} \mathrm{C}$, carefully washed and stained with Alexa goat anti-rabbit secondary antibody (Invitrogen) at 1:500 dilution overnight at $4^{\circ} \mathrm{C}$. For visualization of endothelial cells, cells were incubated with biotinylated Griffonia simplicifolia isolectin-B4 (Vector Laboratories, Burlingame, $\mathrm{CA}$ ) overnight at $4^{\circ} \mathrm{C}$, followed by an overnight incubation at $4{ }^{\circ} \mathrm{C}$ with streptavidin (Alexa Fluor $^{\circledR} 488$ conjugate; Invitrogen). The nucleus was counterstained with Hoechst 33258 (Nakalai Tesque, Kyoto, Japan). Immunofluorescent images were observed under a Leica TCS-SP5 confocal sytem.

The terminal deoxynucleotide transferase-mediated dUTP nick end labeling (TUNEL) technique was conducted to detect apoptotic endothelial cells. The fluorescein in situ cell death detection kit (DeadEnd ${ }^{\mathrm{TM}}$ Fluorometric TUNEL System; Promega, Madison, WI) was used according to the manufacturer's instructions. The fluorosein-labeled cells undergoing apoptosis were recognized as a green fluorescent nucleus. The samples were analyzed using a fluorescence microscope.

\section{DNA fragmentation assay}

To determine the extent of apoptosis, DNA fragmentation was assessed following the method by Arai et al. [30]. In brief, the cells were lysed in a lysis buffer (10
mM Tris, $1 \mathrm{mM}$ EDTA, $0.2 \%$ Triton $\mathrm{X}-100, \mathrm{pH}$ 7.5) and centrifuged at $13,000 \times g$ for $10 \mathrm{~min}$. Subsequently, each DNA sample in the supernatant and the pellet was precipitated in $12.5 \%$ trichloroacetic acid at $4{ }^{\circ} \mathrm{C}$ and quantified using a diphenylamine reagent after hydrolysis in $5 \%$ trichloroacetic acid at $90^{\circ} \mathrm{C}$ for $20 \mathrm{~min}$. After the absorbance of the supernatant and the pellet was determined spectrophotometrically at a wavelength of 600 $\mathrm{nm}$, the percentage of fragmented DNA in each sample was calculated as the amount of DNA in the supernatant divided by the total DNA for that sample (supernatant plus pellet). The average percentage of fragmented DNA in control samples was $2.7 \%$.

\section{Flow cytometry analysis}

Cells were washed with FACS buffer (PBS, 1\% bovine serum albumin, $0.2 \% \mathrm{NaN}_{3}$ ), stained with FITC-labeled anti-human TNF-R1 antibody (clone MABTNFR1-B1; BD Pharmingen, San Diego, CA) for $30 \mathrm{~min}$ at $4^{\circ} \mathrm{C}$, followed by phycoerythrin-labeled goat polyclonal antimouse IgG (clone ab74490, Abcam, Cambridge, England). Propidium Iodide (Sigma-Aldrich, St. Louis, MO) was used to discriminate between dead and live cells. Flow cytometric analysis was performed using FACSCalibur and Cell QuestPro software version 6.0 (BD Biosciences, Franklin Lakes, NJ). TNF-R1 expression was determined using mean fluorescence intensity (MFI), with vehicle-treated cells as the baseline for all comparisons.

\section{Enzyme immunoassay for TNF- $\alpha$}

TNF- $\alpha$ concentrations were determined in cell culture supernatants by enzyme-linked immunosorbent assay (ELISA) (BioVender, Modřice, Česká republika). Sensitivity of the assay was $4 \mathrm{pg} / \mathrm{ml}$ for TNF- $\alpha$. No cross reactivity was observed with other human inflammatory cytokines including various interleukins. Optical density was measured at $450 \mathrm{~nm}$ by use of a microplate reader. Plasma levels of TNF- $\alpha$ were measured by the use of a commercially available enzyme-linked assay kit (Shibayagi Co. Ltd., Shibukawa, Japan) according to the manufacture's instructions.

\section{Mouse model of type 2 diabetes}

The animal study was carried out as approved by the Animal Care and Use Committee of University of Toyama. Male ICR mice, 5-weeks old, received an intraperitoneal injection of $1.5 \mathrm{~g} / \mathrm{kg}$ body weight of nicotinamide dissolved in saline $15 \mathrm{~min}$ before a tail-vein injection of streptozotocin (200 mg/kg; Sigma-Aldrich) dissolved in a citrate buffer solution $(0.1 \mathrm{M}$ citric acid and $0.2 \mathrm{M}$ sodium phosphate, $\mathrm{pH} 4.5$ ), following the protocol previously reported [31,32]. Control mice received the vehicles of both substances. The 
experimental model prepared here was devised more than a decade ago [33]. Its diabetic syndrome appears to share a number of features with human type 2 diabetes [31-33]. Animals were diabetic for 9 weeks before heart harvest. Only animals with glycemia levels above 300 $\mathrm{mg} / \mathrm{dl}$ were used for experiments.

\section{Immunofluorescence and confocal analysis}

Mouse hearts were harvested, fixed with $4 \%$ buffered formalin solution, immersed in sucrose solutions, dipped into OCT compound (Sakura Finetechnical, Tokyo, Japan), and frozen at $-20^{\circ} \mathrm{C}$. The embedded tissues were then sectioned at a thickness of $30 \mu \mathrm{m}$ and air dried. For immunohistochemical detection of the target molecules, the tissue sections were exposed to the fluorescent secondary antibody after incubation with the suitable primary antibody according to the method in our previous study with minor modification [34]. Thus, rehydrated sections were incubated with the primary antibody, anti-mouse CD31 (BD Pharmingen, Franklin Lakes, NJ), anti-mouse TNF-R1 (BD Pharmingen), or anti-mouse Fas (Merck KGaA, Darmstadt, Germany), overnight at $4^{\circ} \mathrm{C}$. The antibodies were used at 1:100 dilution, followed by extensive washes with PBS and incubation with the secondary antibodies conjugated to high quality fluophores, including Alexa Fluor 568, Alexa Fluor 488, and DyLight 488, at 1:500 dilution overnight at $4^{\circ} \mathrm{C}$. The nucleus was counterstained with Hoechst 33258 (Nacalai Tesque, Kyoto, Japan). Immunofluorescent images were observed under Leica TCSSP-5 confocal system (Leica, Wetzlar, Germany).

\section{Statistical analysis}

All experiments were performed at least three times. Data are presented as means \pm SE. Statistical assessment of the data was made by one- or two-way ANOVA, and then differences among groups were analyzed by Turkey's multiple comparison test, with level of significance set at $P<0.05$.

\section{Results}

High glucose-induced endothelial cell apoptosis

The blood clotting protein vWF is synthesized and secreted by endothelial cells. It is a useful maker for endothelial cells, but appears to represent the presence of vascular, especially endothelial, damage and play an important role in thrombosis and inflammation [35]. Immunofluorescent staining for vWF showed that its expression was markedly increased in HCAECs under high glucose conditions (Figure 1). However, it should be noted that this was observed in HCAECs at passage $6 \sim 7$ (used in this study) but not at passage 2, although there was no obvious difference in morphology under microscope observation up to passage 10 (data not shown).

When cells were labeled with an in situ TUNEL assay to detect apoptotic cells, exposure to high glucose resulted in a striking appearance of TUNEL-positive cells (Figure 1). The merge image showed that a positive TUNEL reaction was observed only in vWF positive cells. To quantify high glucose-induced apoptosis, we measured DNA fragmentation in HCAECs. As shown in Figure 2, exposure to high glucose

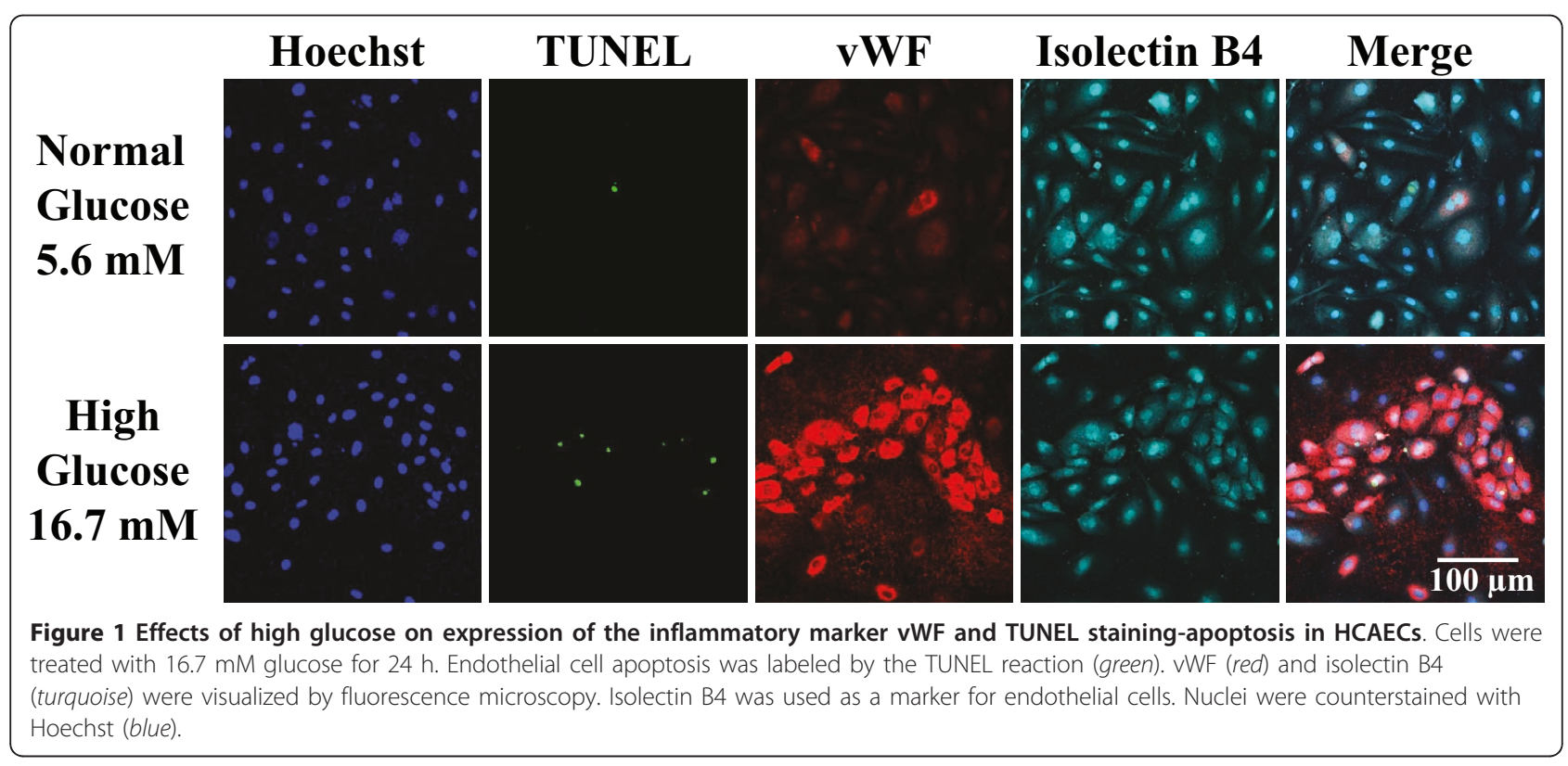




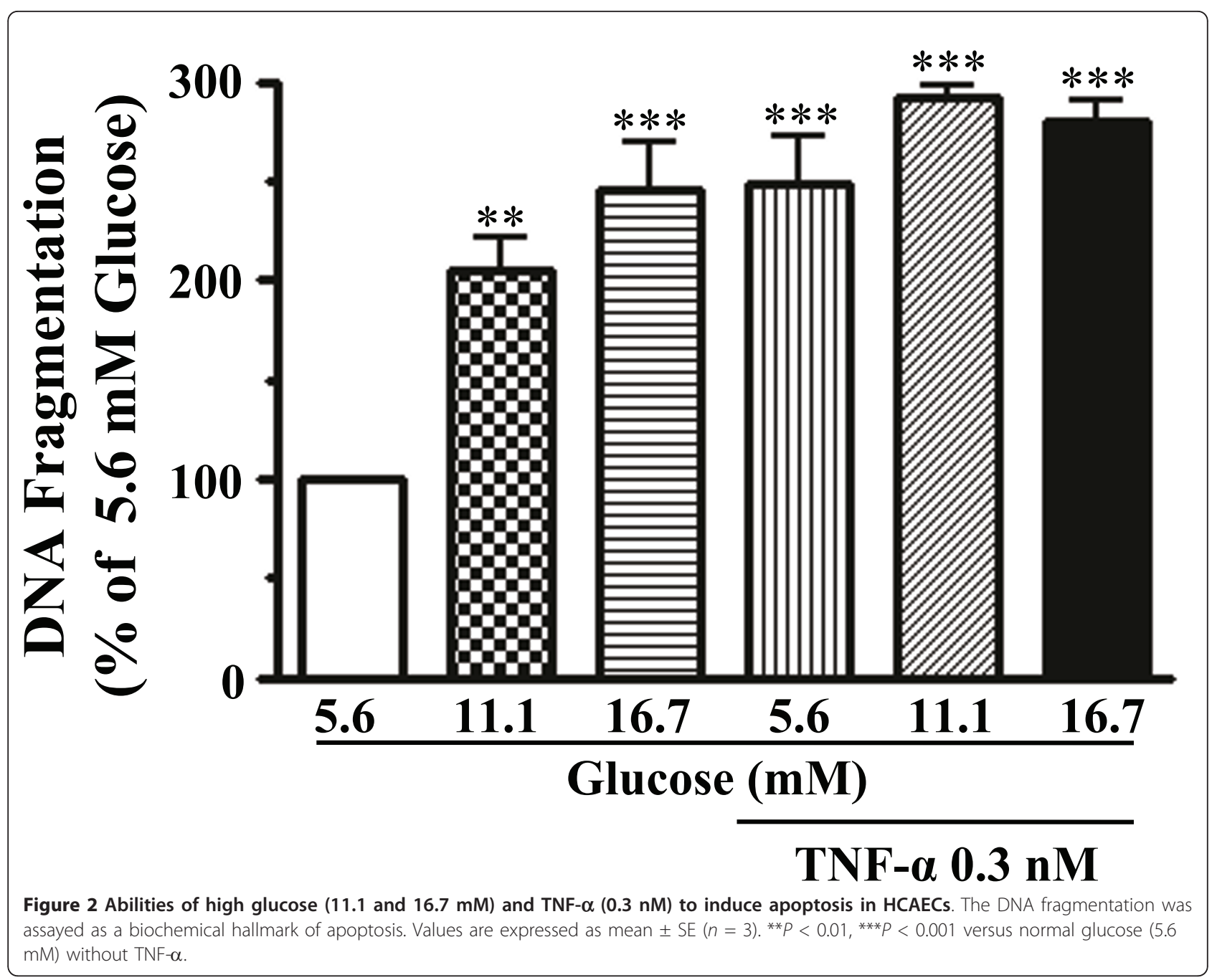

increased DNA fragmentation in a manner dependent on the concentration of glucose. Treatment with TNF$\alpha$ increased DNA fragmentation to the same extent as 16.7 mM glucose did. Combining TNF- $\alpha$ and high glucose exhibited no additive effect compared with high glucose alone.

To rule out an osmotic effect, we added $11 \mathrm{mM}$ mannitol to $5.6 \mathrm{mM}$ glucose. It was confirmed that mannitol was without effect on either vWF expression or cell apoptosis induction (data not shown).

\section{Death receptor expression under high glucose}

To determine how high glucose environment regulates gene expression of death receptors in human endothelial cells, the mRNA expression levels of TNF-R1, Fas, DR4, and DR5 in HCAECs cultured for $24 \mathrm{~h}$ under high glucose conditions were evaluated by PCR analysis (Figure 3). High glucose exposure resulted in a concentration-dependent increase in mRNA expression of TNF-R1. Mannitol, used as an osmolarity control, had no effect on TNF-R1
mRNA expression (data not shown). Another death receptor, Fas, was significantly increased under high glucose conditions, although the extent of up-regulation was less than that seen for TNF-R1. In contrast, mRNA expression levels of DR4 and DR5, both of which mediate TRAIL (TNF related apoptosis inducing ligand)-induced cell death, under high glucose did not significantly differ from those under normal glucose conditions.

Treatment with TNF- $\alpha(0.3 \mathrm{nM})$ strikingly up-regulated mRNA expression levels of all death receptors (Figure 3). High glucose-induced up-regulation of TNF$\mathrm{R} 1$ and Fas mRNA expression was concealed in the presence of TNF- $\alpha$.

We characterized surface expression of TNF-R1 on HCAECs using fluorescence flow cytometry (Figure 4). Histograms generated by flow cytometry software showed that a reproducible shift in TNF-R1 surface expression compared to the mannitol-added control was observed with exposure to high glucose. When TNF- $\alpha$ was further treated under high glucose conditions, the 

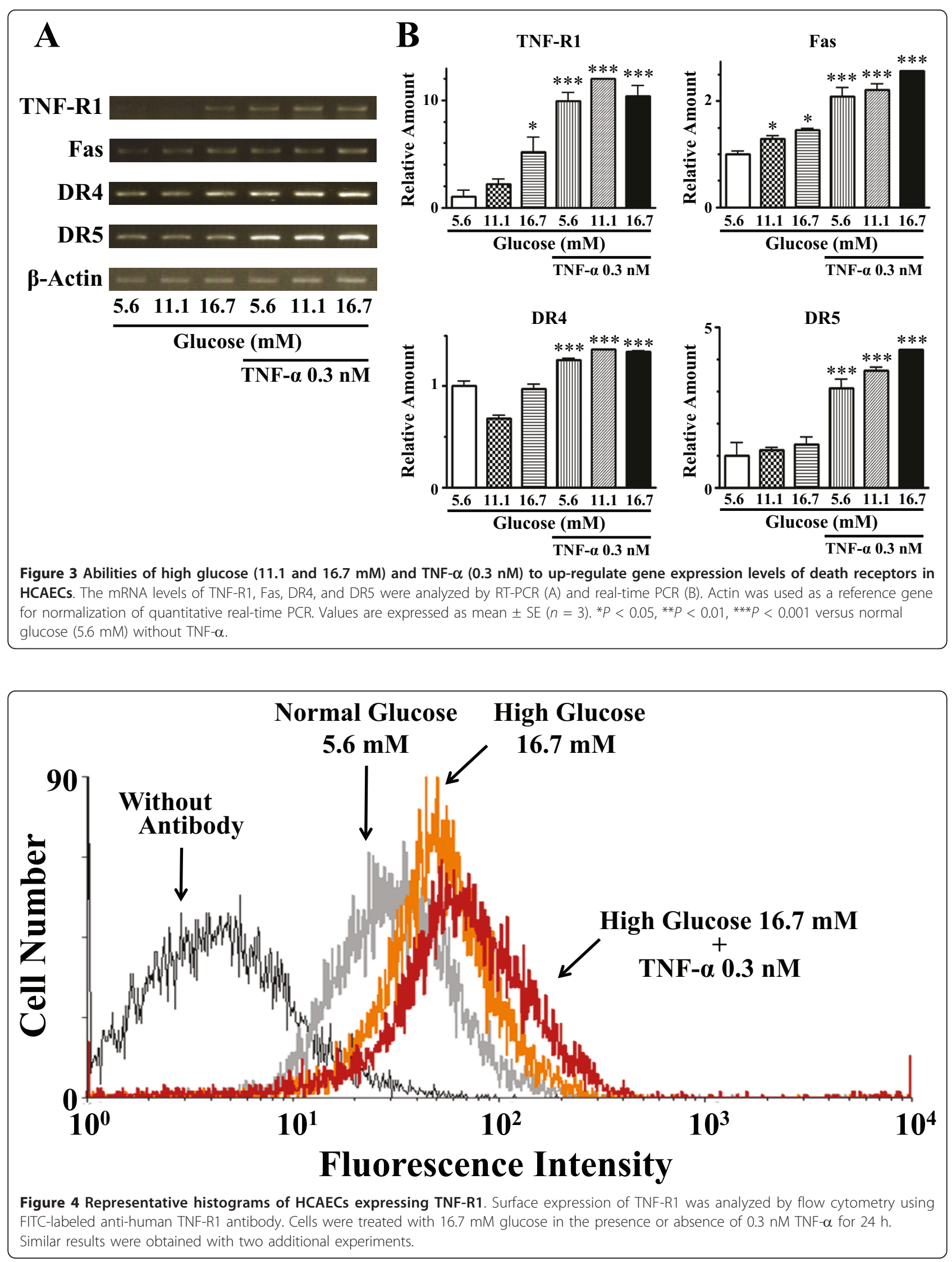
combined effect on surface expression of TNF-R1 was not so pronounced.

\section{Effect of TNF-R1 neutralizing peptides on high glucose- induced apoptosis}

TNF- $\alpha$ concentrations in cell culture supernatants were measured with ELISA. ELISA analysis showed that, under two high glucose conditions (11.1 and $16.7 \mathrm{mM}$ ), TNF- $\alpha$ levels were increased about 3.5- and 5.5-fold, respectively, compared to normal glucose medium (Figure 5A).

When TNF-R1 neutralizing peptides $(80 \mathrm{nM})$ were given during exposure to high glucose, DNA fragmentation caused by high glucose was significantly inhibited by $23 \%$ (Figure $5 \mathrm{~B}$ ). We confirmed that the presence of TNF-R1 neutralizing peptides (20, 40, and $80 \mathrm{nM}$ ) inhibited TNF- $\alpha(0.3 \mathrm{nM})$-induced DNA fragmentation by 15,38 , and $52 \%$, respectively.

\section{Coronary expression of TNF-R1 and Fas in}

type 2 diabetic mice

We generated type 2 diabetic mice which were administered streptozotocin and partially protected with nicotinamide. The non-fasting plasma glucose levels were $149 \pm 28 \mathrm{mg} / \mathrm{dl}(\mathrm{n}=4)$ and $583 \pm 90 \mathrm{mg} / \mathrm{dl}(\mathrm{n}=$ $5)$ for control and diabetic mice, respectively $(p<0.05)$. Plasma TNF- $\alpha$ levels were much higher in diabetic than in control mice $(27.2 \pm 5.4$ vs $6.5 \pm 2.7 \mathrm{pg} / \mathrm{ml}, p<0.05)$. Immunofluorescence staining for TNF-R1 and Fas in the left ventricular cross-sections is shown in Figure 6. Control mice had no positive staining for these death receptors. On the other hand, appreciable positive staining was found in diabetic mice. Overlap images indicated that both TNF-R1 and Fas were expressed on coronary arterial endothelium.

\section{Discussion}

A growing body of evidence has shown that hyperglycemia triggers various vascular endothelial dysfunctions during the development of diabetes. Among them, high glucose-induced endothelial cell apoptosis has been noted in the pathogenesis of the acceleration of atherosclerosis associated with diabetes [6,9]. In the present study, we also demonstrated that, in exposure to high glucose for $24 \mathrm{~h}$, HCAECs can undergo apoptotic cell

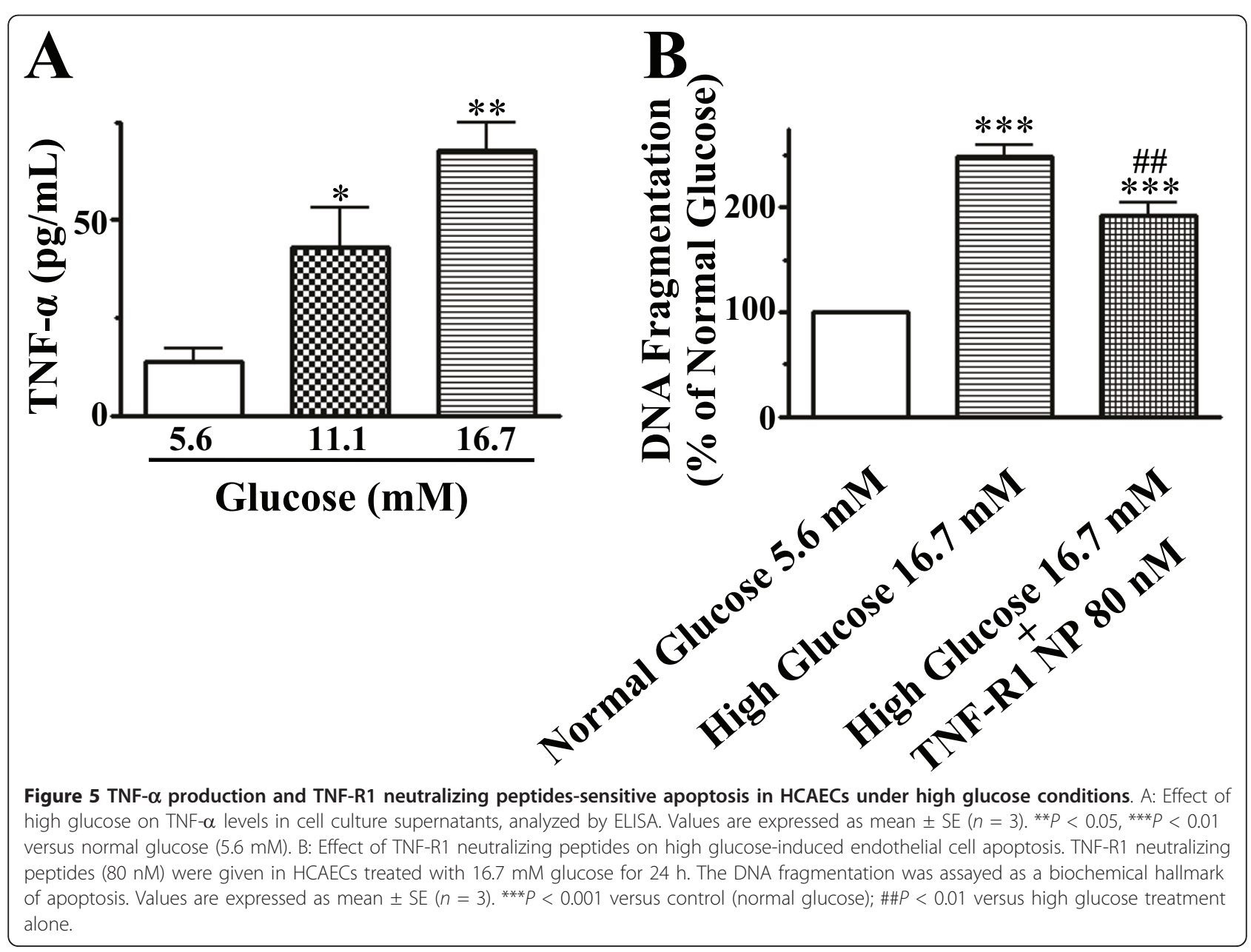




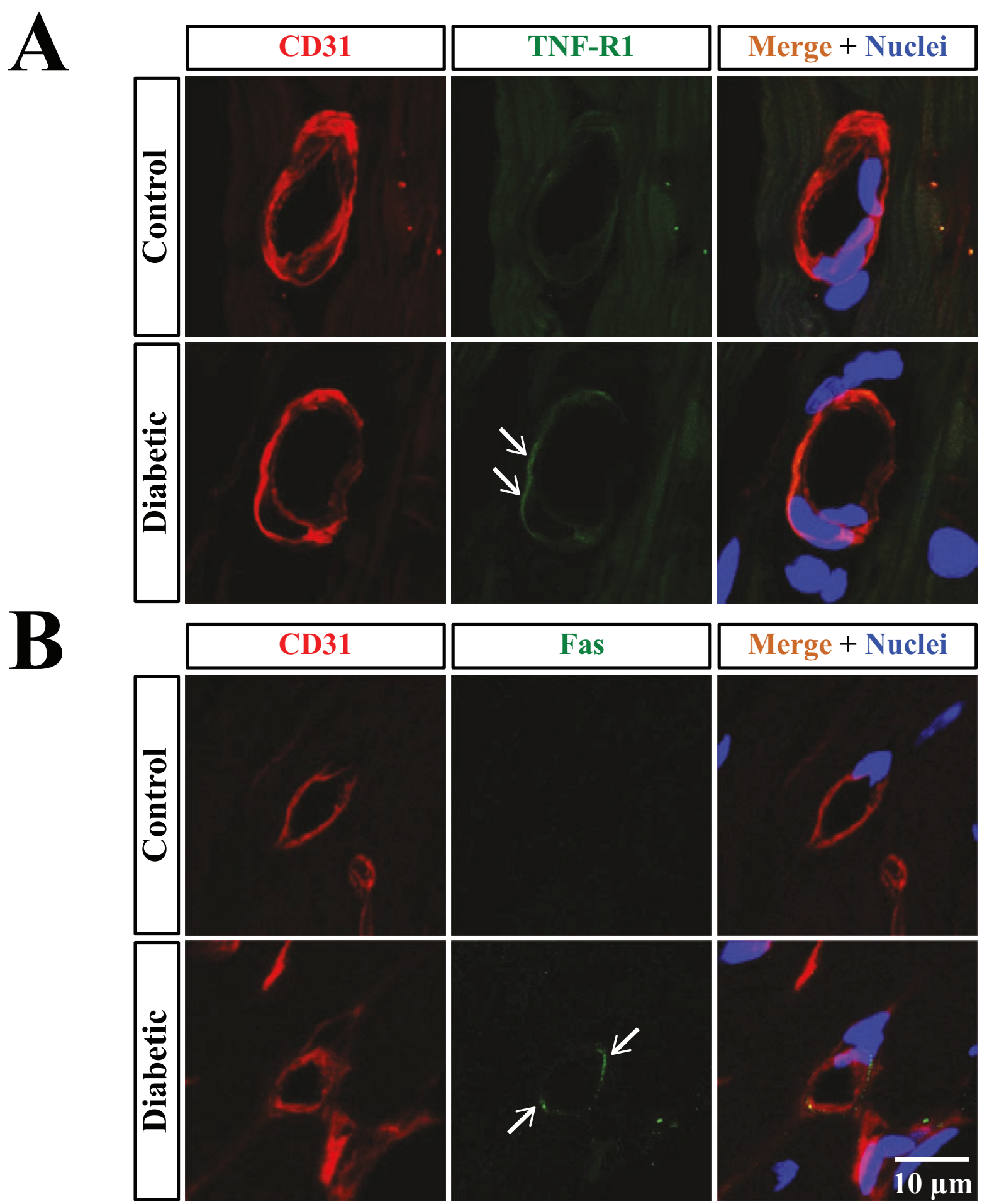

Figure 6 Immunofluorescent images for TNF-R1 (A) and Fas (B) (green, white arrows) in the left ventricular cross-sections from control and nicotinamide-streptozotocin-induced diabetic mice. Coronary arterial endothelial cells are stained with anti-CD31 antibody (red). Overlap images indicate that both TNF-R1 and Fas are present on coronary arterial endothelial cells. Nuclei were counterstained with Hoechst (blue). Shown are representative micrographs from two independent experiments in which the same results were obtained. 
death. Analysis of in situ TUNEL assay and DNA fragmentation provides clear experimental evidence for high glucose-induced apoptosis in HCAECs.

Previous works have indicated that high glucose treatment increases Bax protein, an accelerator of apoptosis, which in turn releases cytochrome $c$ from mitochondria. The released cytochrome $c$ into cytoplasm can bind to Apaf-1, resulting in activation of the caspase cascade that induces apoptosis [21,22]. Thus, cytochrome $c$ released from mitochondria has been thought to be important in high glucose-induced endothelial cell apoptosis. We found that gene and surface protein expression levels of TNF-R1 and Fas were highly up-regulated in HCAECs under high glucose conditions. High glucose-triggered death receptor up-regulation in human endothelial cells was not due to changes in osmolarity, because no increase in these death receptors was seen in HCAECs treated with the osmotic control mannitol. Furthermore, high ambient glucose did not lead to a significant up-regulation of DR4 and DR5 in HCAECs, both of which are known to be receptors for TRAIL [36]. Our present findings would suggest the pathophysiological significance of the ligand-specific death receptor apoptotic signaling pathway, in addition to the intrinsic mitochondrial-mediated apoptotic signaling pathway, in high glucose-induced human endothelial cell apoptosis.

Apparent increases in plasma concentrations of proinflammatory cytokines, including TNF- $\alpha$, seem to be seen in subjects with obesity and insulin resistance [37]. It has been shown that expression of TNF- $\alpha$ as well as other proinflammatory cytokines and chemokines is regulated by glucose in human monocytes and monocytic cell lines [38-40]. Thus, high glucose treatment activates these cells and induces an increase in gene expression of TNF- $\alpha$. We found that high glucose exposure of HCAECs resulted in a marked increase in TNF$\alpha$ levels in cell culture supernatants. High glucoseinduced high expression of TNF- $\alpha$ has also been demonstrated in cultured cardiomyocytes of neonatal rats [41]. To the best of our knowledge, however, this is the first to demonstrate the high glucose-induced increases in TNF- $\alpha$ production by human endothelial cells. In light of the up-regulation of TNF-R1, a membrane receptor that mediates cytotoxicity elicited by TNF- $\alpha$, in HCAECs under high glucose conditions, we interpret this finding to indicate that the TNF- $\alpha$ system may play a key part in high glucose-induced endothelial cell apoptosis.

Treatment with TNF- $\alpha$ in normal glucose medium caused a marked up-regulation of mRNA levels of death receptors in HCAECs. Therefore, TNF- $\alpha$ appears to be a major determinant of high glucose-induced up-regulation of TNF-R1 and Fas expression in endothelial cells.
Consistent with this is the finding that high glucose resulted in no further up-regulation of TNF-R1 and Fas mRNA expression in the presence of TNF- $\alpha$. However, high glucose-induced up-regulation of TNF-R1 and Fas cannot be solely attributed to the increased TNF- $\alpha$ production by endothelial cells exposed to high glucose. Endothelial expression of DR4 and DR5 mRNAs was strikingly up-regulated by TNF- $\alpha$ treatment but not by high glucose exposure. Experimental evidence for the regulatory mechanism(s) by which TNF- $\alpha$ can increase gene expression of these TRAIL receptors awaits further study.

A potential role of the TNF- $\alpha$ system in high glucoseinduced human endothelial cell apoptosis was tested with TNF-R1 neutralizing peptides when given at a concentration of $80 \mathrm{nM}$. TNF-R1 neutralizing peptides showed a significant inhibition of high glucose-induced DNA fragmentation in HCAECs. This suggests that the TNF- $\alpha$ system is involved in human endothelial cell apoptosis induction under high glucose conditions. However, the inhibitory effect of TNF-R1 neutralizing peptides was less than $40 \%$. It should be noted that the dose of TNF-R1 neutralizing peptides employed in this study caused $>50 \%$ inhibition of $0.3 \mathrm{nM}$ TNF- $\alpha$-induced DNA fragmentation in HCAECs. Alternatively, the Fas/ Fas ligand system as well as the intrinsic mitochondrialmediated apoptotic signaling pathway may be additional mechanisms for the remaining effect of high ambient glucose to induce human endothelial cell apoptosis. The involvement of the Fas/Fas ligand system in high glucose-induced apoptosis of human islets has been demonstrated using the antagonistic anti-Fas antibody ZB4 [42]. It may be considered that dual treatment with TNF-R1 neutralizing peptide and ZB4 could suppress high glucose-induced DNA fragmentation more efficiently than TNF-R1 neutralizing peptide alone.

Exposure of endothelial cells to excess glucose has been reported to induce inflammation $[43,44]$. The underlying mechanisms are thought to be related to accumulation of proinflammatory intermediates or byproducts such as reactive oxygen species. In this study, the inflammatory marker vWF was strongly expressed in HACECs when treated with high glucose. Importantly, the merge image showed that a positive TUNEL reaction was observed only in vWF positive cells. This implies that apoptosis may be specifically induced in inflammatory endothelial cells. In endothelial cells under high glucose conditions, increased inflammation could lead to enhanced apoptosis. Although the inflammatory process involves the activation of the transcription factor nuclear factor $-\kappa \mathrm{B}(\mathrm{NF}-\kappa \mathrm{B})$ that is often associated with a predominantly antiapoptotic role through its ability to up-regulate cytoprotective gene products, the induction of the potential regulator that globally induces 
expression of proapoptotic genes may represent a mechanism to overcome NF- $\kappa \mathrm{B}$-associated antiapoptosis [45].

Finally, our immunofluorescence study found that chronic type 2 diabetic mice showed appreciable expression of TNF-R1 and Fas in the intimal surface of coronary arterioles. No positive staining for these death receptors was obtained in age-matched control mice. Circulating TNF- $\alpha$ levels were elevated in diabetic mice as reported in diabetic patients as well as in streptozotocin-induced diabetic rats $[46,47]$. Also, Fas ligand, whose expression is limited to cells of the immunosystem, has been shown to be significantly up-regulated in diabetic rat neutrophils [48]. Therefore, induction of death receptor expression in coronary arteriolar endothelium may promote coronary endothelial cell apoptosis during chronic diabetes. It is striking that there is a clinical study showing increases in apoptosis of cardiomyocytes, endothelial cells, and fibroblasts in specimens of myocardial tissues from diabetic patients [11].

In conclusion, the present study showed that the death receptors, TNF-R1 and Fas, are up-regulated in HCAECs under high glucose conditions. This up-regulation of death receptor expression, coupled with increased TNF- $\alpha$ secretion, could promote endothelial cell apoptosis, which is likely to contribute to coronary arterial endothelial dysfunction and the development of ischemic heart disease in diabetes.

\section{Acknowledgements}

We thank Prof. Makoto Kadowaki for guidance in various methodological aspects of the study. This work was supported in part by a Grant-in-Aid for Scientific Research from the Ministry of Education, Culture, Sports, Science and Technology of Japan.

\section{Author details}

'Department of Molecular and Medical Pharmacology, Graduate School of Medicine and Pharmaceutical Sciences, University of Toyama, Toyama 9300194, Japan. ${ }^{2}$ Division of Gastrointestinal Pathophysiology, Department of Bioscience, Institute of Natural Medicine, University of Toyama, Toyama 9300194, Japan.

\section{Authors' contributions}

SK, HY, NM, and YH designed research; SK, HY, KT, NK-Y, SY, and RY performed research; SK, HY, and KT analyzed data; SK, HY, and $Y H$ wrote the paper. All authors have read and approved submission of the final manuscript.

\section{Conflicts of interests}

The authors declare that they have no competing interests.

Received: 22 April 2011 Accepted: 4 August 2011

Published: 4 August 2011

\section{References}

1. Lorenzi M, Cagliero E: Pathobiology of endothelial and other vascular cells in diabetes mellitus. Diabetes 1991, 40:653-659.

2. Hink U, Li H, Mollnau H, Oelze M, Matheis E, Hartmann M, Skatchkov M, Thaiss F, Stahl RA, Warnholtz A, Meinertz T, Griendling K, Harrison DG, Forstermann U, Muzel T: Mechanisms underlying endothelial dysfunction in diabetes mellitus. Circ Res 2001, 88:E14-E22.
3. Lorenzi M, Cagliero E, Toledo S: Glucose toxicity for human endothelial cells in culture: delayed replication, disturbed cell cycle, and accelerated death. Diabetes 1985, 34:621-627.

4. Lorenzi M, Nordberg JA, Toledo S: High glucose prolongs cell-cycle traversal of cultured human endothelial cells. Diabetes 1987, 36:1241-1267.

5. Lorenzi M, Montisano DF, Toledo S, Barrieux A: High glucose induces DNA damage in cultured human endothelial cells. J Clin Invest 1986, 77:322-325.

6. Baumgartner-Parzer SM, Wagner L, Pettermann M, Grillari J, Gessl A, Waldhausl W: High-glucose-triggered apoptosis in cultured endothelial cells. Diabetes 1995, 44:1323-1327.

7. Du XL, Sui GZ, Stockklauser-Farber K, Weiss J, Zink S, Schwippert B, Wu QX Tschope D, Rosen P: Introduction of apoptosis by high proinsulin and glucose in cultured human umbilical vein endothelial cells is mediated by reactive oxygen species. Diabetologia 1998, 41:249-256.

8. Wu QD, Wang JH, Fennessy F, Redmond HP, Bouchier-Hayes D: Taurine prevents high-glucose-induced human vascular endothelial cell apoptosis. Am J Physiol 1999, 277:C1229-C1238.

9. Ho FM, Liu SH, Liau CS, Huang PJ, Lin-Shiau SY: High glucose-induced apoptosis in human endothelial cells is mediated by sequential activation of c-Jun $\mathrm{NH}_{2}$-terminal kinase and caspase-3. Circulation 2000, 101:2618-2624.

10. Busik JV, Mohr S, Grant MB: Hyperglycemia-induced reactive oxygen species toxicity to endothelial cells is dependent on paracrine mediators. Diabetes 2008, 57:1952-1965.

11. Mizutani M, Kern TS, Lorenzi M: Accelerated death of retinal microvascular cells in human and experimental diabetic retinopathy. J Clin Invest 1996, 97:2883-2890.

12. Behl Y, Krothapalli $P$, Desta T, Roy S, Graves DT: FOXO1 plays an important role in enhanced microvascular cell apoptosis and microvascular cell loss in type 1 and type 2 diabetic rats. Diabetes 2009, 58:917-925.

13. Frustaci A, Kajstura J, Chimenti C, Jakoniuk I, Leri A, Maseri A, NadalGinard B, Anversa P: Myocardial cell death in human diabetes. Circ Res 2000, 87:1123-1132.

14. Ido Y, Carling D, Ruderman N: Hyperglycemia-induced apoptosis in human umbilical vein endothelial cells: inhibition by the AMP-activated protein kinase activation. Diabetes 2002, 51:159-167.

15. Recchioni R, Marchesselli F, Moroni F, Pieri C: Apoptosis in human aortic endothelial cells induced by hyperglycemic condition involves mitochondria depolarization and is prevented by $\mathrm{N}$-acetyl-L-cysteine. Metabolism 2002, 51:1384-1388.

16. Min C, Kang E, Yu SH, Shinn SH, Kim YS: Advanced glycation and products induce apoptosis and procoagulant activity in cultured human umbilical vein endothelial cells. Diabetes Res Clin Pract 1999, 46:197-202.

17. Chen J, Brodsky SV, Goligorsky DM, Hampel DJ, Li H, Gross SS, Goligorsky MS: Glycated collagen I induces premature senescence-like phenotype changes in endothelial cells. Circ Res 2002, 90:1290-1298.

18. Sakuma H, Yamamoto M, Okumura M, Kojima T, Maruyama T, Yasuda K: High glucose inhibits in human coronary artery smooth muscle cells by increasing bcl-xL and bfl-1/A1. Am J Physiol Cell Physiol 2002, 283: C422-C428.

19. Korsmeyer SJ: BCL-2 gene family and the regulation of programmed cell death. Cancer Res 1999, 59(Suppl 7):1693s-1700s.

20. Green DR, Kroemer G: The pathophysiology of mitochondrial cell death Science 2004, 305:626-629.

21. Li Y, Wu H, Khardori R, Song Y-H, Lu YW, Geng Y-J: Insulin-like growth factor-1 receptor activation prevents high glucose-induced mitochondrial dysfunction, cytochrome-c release and apoptosis. Biochem Biophys Res Commun 2009, 384:259-264.

22. Nakagami H, Morishita R, Yamamoto K, Yoshimura S, Taniyama Y, Aoki M, Matsubara H, Kim S, Kaneda Y, Ogihara T: Phosphorylation of p38 mitogen-activated protein kinase downstream of Bax-caspase-3 pathway leads to cell death induced by high D-glucose in human endothelial cells. Diabetes 2001, 50:1472-1481.

23. Thorburn A: Death receptor-induced cell killing. Cell Signal 2004, 16:139-144.

24. Lavrik I, Golks A, Krammer PH: Death receptor signaling. J Cell Sci 2005 , 118:265-267.

25. Su X, Hu Q, Kristan JM, Costa C, Shen Y, Gero D, Matis LA, Wang Y: Significant role for Fas in the pathogenesis of autoimmune diabetes. $J$ Immunol 2000, 164:2523-2532. 
26. Allison J, Thomas HE, Catterall T, Kay TW, Strasser A: Transgenic expression of dominant-negative Fas-associated death domain protein in $\beta$ cells protects against Fas ligand-induced apoptosis and reduces spontaneous diabetes in nonobese diabetic mice. J Immunol 2005, 175:293-301.

27. Dudek NL, Thomas HE, Mariana L, Sutherland RM, Allison J, Estella E, Angstetra E, Trapani JA, Santamaria P, Lew AM, Kay TW: Cytotoxic T-cells from T-cell receptor transgenic NOD8.3 mice destroy beta-cells via the perforin and Fas pathways. Diabetes 2006, 55:2412-2418.

28. Kim YH, Kim S, Kim KA, Yagita H, Kayagaki N, Kim KW, Lee MS: Apoptosis of pancreatic $B$ cells detected in accelerated diabetes of NOD mice: no role of Fas-Fas ligand interation in autoimmune diabetes. Eur J Immunol 1999 29:455-465.

29. Kim S, Kim KA, Hwang DY, Lee TH, Kayagaki N, Yagita H, Lee MS: Inhibition of autoimmune diabetes by Fas ligand: the paradox is solved. J Immunol 2000, 164:2931-2936.

30. Arai Y, Kondo T, Tanabe K, Zhao Q-L, Li F-J, Ogawa R, Li M, Kasuya M: Enhancement of hyperthermia-induced apoptosis by local anesthetics on human histiocytic lymphoma U937 cells. J Biol Chem 2002, 277:18986-18993.

31. Kobayashi T, Taguchi K, Yasuhiro T, Matsumoto T, Kamata K: Impairment of $\mathrm{PI3-K/Akt} \mathrm{pathway} \mathrm{underlies} \mathrm{attenuated} \mathrm{endothelial} \mathrm{function} \mathrm{in} \mathrm{aorta} \mathrm{of}$ type 2 diabetic mouse model. Hypertension 2004, 44:956-962.

32. Takenouchi Y, Kobayashi T, Taguchi K, Matsumoto T, Kamata K: Gender differences in endothelial function in aortas from type 2 diabetic model mouse. J Pharmacol Sci 2009, 111:91-99.

33. Masiello P, Broca C, Gross R, Roye M, Manteghetti M, Hillaire-Buys D, Novelli M, Ribes G: Experimental NIDDM. Development of a new model in adult rats administered streptozotocin and nicotinamide. Diabetes 1998, 47:224-229.

34. Kamiyama K, Matsuda N, Yamamoto S, Takano K, Takano Y, Yamazaki H, Kageyama S, Yokoo H, Nagata T, Hatakeyama N, Tsukada K, Hattori Y: Modulation of glucocorticoid receptor expression, inflammation, and cell apoptosis in septic guinea pig lungs using methylprednisolone. Am J Physiol Lung Cell Mol Physiol 2008, 295:L998-L1006.

35. Vischer UM: von Willebrand factor, endothelial dysfunction, and cardiovascular disease. J Thromb Haemost 2006, 4:1186-1193.

36. Thorburn A: Death receptor-induced cell killing. Cell Signal 2004, 16:139-144.

37. Moller DE: Potential role of TNF-a in the pathogenesis of insulin resistance and type 2 diabetes. Trends Endocrinol Metab 2000, 11:212-217.

38. Morohoshi M, Fujisawa K, Uchimura I, Numano F: Glucose-dependent interleukin 6 and tumor necrosis factor production by human peripheral blood monocytes in vitro. Diabetes 1996, 45:954-959.

39. Guha M, Bai W, Nadler JL, Natarajan R: Molecular mechanisms of tumor necrosis factor a gene expression in monocytic cells via hyperglycemiainduced oxidant stress-dependent and -independent pathways. J Biol Chem 2000, 275:17728-17739.

40. Shanmugam N, Reddy MA, Guha M, Natarajan R: High glucose-induced expression of proinflammatory cytokine and chemokine genes in monocytic cells. Diabetes 2003, 52:1256-1264.

41. Min W, Bin ZW, Quan ZB, Hui ZJ, Sheng FG: The signal transduction pathway of PKC/NF-KB/C-fos may be involved in the influence of high glucose on the cardiomyocytes of neonatal rats. Cardiovasc Diabetology 2009, 8:8.

42. Maedler K, Spinas GA, Lehmann R, Sergeev P, Weber M, Fontana A, Kaiser N, Donath MY: Glucose induces $\beta$-cell apoptosis via upregulation of the Fas receptor in human islets. Diabetes 2001, 50:1683-1690.

43. Kim F, Tysseling KA, Rice J, Gallis B, Haji L, Giachelli CM, Raines EW, Corson MA, Schwartz MW: Activation of IKK $\beta$ by glucose is necessary and sufficient to impair insulin signaling and nitric oxide production in endothelial cells. J Mol Cell Cardiol 2005, 39:327-334.

44. Toma L, Stancu CS, Botez GM, Sima AV, Simionescu M: Irreversibly glycated LDL induce oxidative and inflammatory state in human endothelial cells; added effect of high glucose. Biochem Biophys Res Commun 2009, 390:877-882.

45. Alikhani M, Alikhani Z, Graves D: FOXO1a functions as a master switch that regulates gene expression necessary for TNF-induced fibroblast apoptosis. J Biol Chem 2005, 280:12096-12102.

46. Jain SK, Kannan K, Lim G, McVie R, Bocchini JA Jr: Hyperketonemia increases tumor necrosis factor-a secretion in cultured U937 monocytes and type 1 diabetic patients and is apparently mediated by oxidative stress and cAMP deficiency. Diabetes 2002, 51:2287-2293.

47. El-Seweidy MM, El-Swefy SE, Ameen RS, Hashem RM: Effect of age receptor blocker and/or anti-inflammatory coadministration in relation to glycation, oxidative stress and cytokine production in STZ diabetic rats. Pharmacol Res 2002, 45:391-398.

48. Joussen AM, Poulaki V, Mitsiades N, Cai W, Suzuma I, Pak J, Ju S-T, Rook SL, Esser P, Mitsiades C, Kirchhof B, Adamis AP, Aiello LP: Suppression of FasFasL-induced endothelial cell apoptosis prevents diabetic blood-retinal barrier breakdown in a model of streptozotocin-induced diabetes. FASEB J 2003, 17:76-78.

doi:10.1186/1475-2840-10-73

Cite this article as: Kageyama et al:: High glucose-induced apoptosis in human coronary artery endothelial cells involves up-regulation of death receptors. Cardiovascular Diabetology 2011 10:73.

\section{Submit your next manuscript to BioMed Central and take full advantage of:}

- Convenient online submission

- Thorough peer review

- No space constraints or color figure charges

- Immediate publication on acceptance

- Inclusion in PubMed, CAS, Scopus and Google Scholar

- Research which is freely available for redistribution

Submit your manuscript at www.biomedcentral.com/submit
C Biomed Central 